\title{
La fabrique des entités : récits sur l'enchantement d'un riverain extraordinaire en Amazonie brésilienne
}

Making New Entities: Narratives about the Enchantment of an Extraordinary Man in the Brazilian Amazon

A produção de entidades: Narrativas sobre o encantamento de uma pessoa extraordinária na Amazônia brasileira

\section{Émilie Stoll}

\section{OpenEdition}

Journals

Édition électronique

URL : https://journals.openedition.org/clo/2792

DOI : $10.4000 /$ clo.2792

ISSN : 2266-1816

Éditeur

INALCO

Édition imprimée

Date de publication : 1 janvier 2016

ISBN : 9782858312337

ISSN : 0396-891X

Référence électronique

Émilie Stoll, «La fabrique des entités : récits sur l'enchantement d'un riverain extraordinaire en Amazonie brésilienne », Cahiers de littérature orale [En ligne], 79 | 2016, mis en ligne le 20 décembre 2016, consulté le 30 juin 2021. URL : http://journals.openedition.org/clo/2792 ; DOI : https://doi.org/ $10.4000 /$ clo. 2792

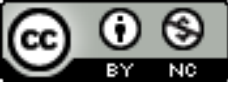

Cahiers de littérature orale est mis à disposition selon les termes de la Licence Creative Commons Attribution - Pas d'Utilisation Commerciale 4.0 International. 


\title{
La fabrique des entités : récits sur l'enchantement d'un riverain extraordinaire en Amazonie brésilienne
}

\author{
Émilie STOLL \\ UMR 208 Patrimoines locaux et gouvernance IRD/MNHN
}

En janvier 2011, j'ai commencé une enquête de terrain ${ }^{1}$ dans de petits villages riverains de la zone rurale de Santarém, ville amazonienne de 300000 habitants, localisée à la confluence du Tapajós et de l'Amazone, dans l'État du Pará, au Brésil. Les villages de la rivière Arapiuns (dernier affluent du Tapajós) étaient traversés par des conflits présentés comme identitaires depuis qu'une partie des familles se revendiquait « indigène », tandis que les autres familles considéraient être des « populations traditionnelles ». En effet, la législation brésilienne prévoit diverses catégories légales à partir de critères ethnico-raciaux et/ou d'usages des ressources, auxquelles sont associés des droits territoriaux (démarcation de terres indigènes ou de réserves écologiques) et sociaux. Dans ces villages, ces affiliations identitaires divergentes étaient sources de tensions entre des groupes qui étaient par ailleurs liés entre eux par des liens de parenté (voir Stoll, 2014). À mon arrivée dans le village Lago da Praia, les habitants indigènes m'indiquèrent une avancée de

1. Deux relecteurs anonymes ont contribué par leurs commentaires à l'amélioration de ce texte. Omaira Bolaños Cárdenas, Roxani Rivas Ruiz, Ray Troll, Ana Carla Bruno et les administrateurs du blog « No Amazonas é assim » m’ont gentiment donné leur autorisation pour publier des illustrations extraites de leurs travaux. L'enquête de terrain a été financée par une bourse du CNPq/INPE (Geoma 2). J'ai également bénéficié du soutien financier et institutionnel de l'ANR Fabriq'Am, du programme Capes-Cofecub, ainsi que de l'Université d'Aberdeen et de la Fondation Fyssen. Qu'ils en soient chaleureusement remerciés. 
sable sur la rivière qui, selon eux, était le lieu de résidence actuel de Merandolino, un chamane-guérisseur (pajé) ayant vécu jusqu'au début du $\mathrm{Xx}^{\mathrm{e}}$ siècle. La « pointe de Toronó » (figures 2 et 3 ) était l'endroit où cet homme «s'était enchanté » en place et lieu du trépas ${ }^{2}$. Depuis lors, Merandolino était devenu un encantado, c'est-à-dire l'un de ces êtres enchantés qui résident dans une « cité enchantée » (cidade encantada) subaquatique (figure 5) et qui, éventuellement, servent d'esprits auxiliaires à certains guérisseurs. La pointe de Toronó est considérée par les Indigènes comme un « lieu sacré » (lugar sagrado). Elle sert de balise topographique dans le périmètre proposé pour la démarcation de leur territoire, qui a été baptisé « terre indigène Cobra Grande » ${ }^{3}$ justement en référence à Merandolino, comme le raconte une chanson composée par un dirigeant indigène local.

En effet, les riverains racontent que ce guérisseur se déplaçait sous l'eau « enroulé dans une peau de Cobra Grande », c'est-à-dire d'anaconda géant. L'objet de cet article est de soumettre à l'analyse un ensemble de récits au sujet de la vie de Merandolino, le plus célèbre guérisseur de la rivière Arapiuns, décédé dans les années 1940. Dans un premier temps, je décrirai le corpus de textes où l'on voit que la plupart des récits sont racontés par les gens du commun à la manière des histórias : les protagonistes de l'histoire et le narrateur sont localisés socialement et spatialement dans le réseau d'interconnaissance régional et ils sont mis en scène dans des situations extraordinaires, à partir de motifs amplement répandus dans la région. Dans un deuxième temps, j'expliquerai comment, dans des contextes d'énonciation précis, lorsque le conteur est un guérisseur, ces récits peuvent intégrer dans leur trame narrative des épisodes du mythe de Cobra Honorato. Enfin, je ferai une lecture sociologique de ces récits en partant des faisceaux d'indices qui s'y trouvent toujours, quel que soit le narrateur, et qui visent à situer Merandolino dans un espace régional hétérogène chargé d'enjeux sociaux, politiques et économiques. Je conclurai en proposant que ces récits de vie, informés par d'autres genres narratifs, comme le mythe ou le récit-type (manière stéréotypée de raconter un évènement), participent à faire de Merandolino un personnage extraordinaire, presque légendaire. La fabrication de la légende n'efface pas pour autant les détails sociologiques de l'affaire, qui deviennent centraux dans le récit, participant à

2. Le processus d'enchantement est formulé ainsi : « Merandolino s'est enchanté (ele se encantou) sur la pointe de Toronó ». Les riverains disent qu'il «n'est pas mort » et que son corps a disparu du cercueil.

3. La terre indigène Cobra Grande a été identifiée par la FUNAI (Fondation Nationale de l'Indien) le 29 septembre 2015. Il s'agit de la première étape du processus de démarcation. 
entretenir et à nourrir les discours identitaires actuels des populations riveraines de l'Arapiuns.

\section{Des récits ordinaires sur un homme extraordinaire}

\section{Merandolino Cobra Grande de l'Arapiuns}

Merandolino a vécu le long de la rivière Arapiuns entre la fin du XIX ${ }^{\mathrm{e}}$ siècle et les années 1940. Ce riverain avait cependant une particularité : c'était un talentueux guérisseur, un pajé sacaca (termes en Nheengatú utilisés localement pour désigner les guérisseurs les plus puissants) dont les prouesses extraordinaires sont encore commentées jusqu'à nos jours. Tout le monde, dans l'Arapiuns, sait raconter l'histoire, au moins dans ses grands traits, de Merandolino Cobra Grande. Né avec le don de guérison, il s'est fait connaître grâce à la réputation qu'il avait de se déplacer sous l'eau à vive allure, enroulé dans une peau d'anaconda géant. L'homme habitait en amont de la rivière, à Mentai, et il parvenait avec ce véhicule subaquatique à précéder l'arrivée, à la ville de Santarém, de son propre bateau. La peau d'anaconda de Merandolino, «c'était une sorte de vedette [bateau rapide à moteur] ! » me commentait une jeune fille d'une vingtaine d'années. Merandolino pouvait également rester immergé sous l'eau pendant plusieurs jours. Lorsqu'il réapparaissait à la surface, son cigare était encore allumé. Ces récits font appel à un motif très présent en Amazonie, celui de l'anaconda, véhicule entre les mondes ${ }^{4}$ (Tastevin, 1925 ; Galvão, 1976 ; Faulhaber, 1998, p. 154; Chaumeil, 2003, p. 40 ; Gentil et Bruno, 2007, p. 239 ; Rivas Ruiz, 2011)

4. « Les [Indiens] Tukano sont sortis du Lago de Leite dans le canoë de l'anaconda, qu'on appelle Pãmëri piroYukësë. C'est de cette manière qu'ils se sont dispersés dans tous les coins de la terre, et sont devenus des humains normaux » (GENTIL et BRUNO, 2007, p. 239, URL: http://www.scielo.br/pdf/hcsm/v14s0/10.pdf, ma traduction). 


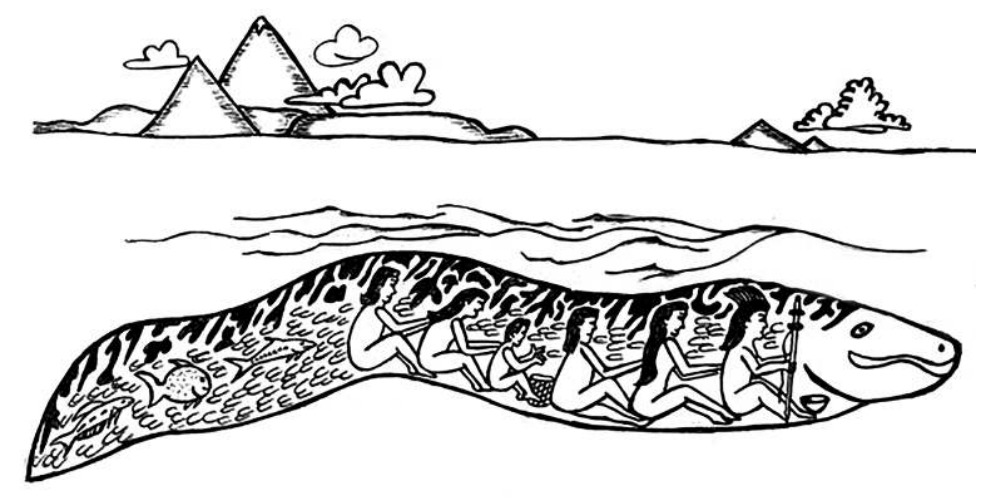

Figure 1

Embarcation-anaconda tukano, véhicule entre les mondes

(c) Gabriel Gentil, in : Gentil et Bruno, 2007, p. 239

Dans le bas-Amazone, comme ailleurs, les pajés sacacas naviguent sous la forme d'anacondas entre la terre et la « cité enchantée », demeure subaquatique des encantados, les êtres enchantés. Le destin post-mortem de ces grands guérisseurs est de devenir à leur tour les entités auxiliaires des guérisseurs encore vivants. Ce passage définitif d'un état d'être humain vivant sur terre à celui d'entité subaquatique est appelé « enchantement ». En général, les riverains considèrent qu'il y a eu enchantement lorsque le corps du défunt « disparaît » du cercueil. Il en est de même pour les personnes qui disparaissent sans que l'on retrouve leur corps ou que l'on ait pu identifier avec certitude qu'elles sont décédées. Chaque individu enchanté est invité à construire sa nouvelle demeure à un étage inférieur du monde des humains, dans un lieu précis de la cité enchantée. Celle-ci reproduit la forme et les contours de la surface terrestre, si bien que les guérisseurs défunts - comme tous les humains enchantés d'ailleurs - s' « enchantent » quelque part, à un emplacement subaquatique précis qui correspond en surface à un lieu connu et potentiellement habité par les humains. Ces endroits auxquels sont associés des habitats enchantés correspondent à des saillances paysagères et/ou écologiques : plages inondables, criques, monticules, embranchements aquatiques, mangroves, etc. Ils prennent alors l'appellation d' « enchantements » (encantes) et sont soumis à certaines règles d'accès et d'usage en raison de leur qualité d'habitat d'en- 
tité subaquatique. C'est ainsi que Merandolino «s'est enchanté sur la pointe de Toronó ».

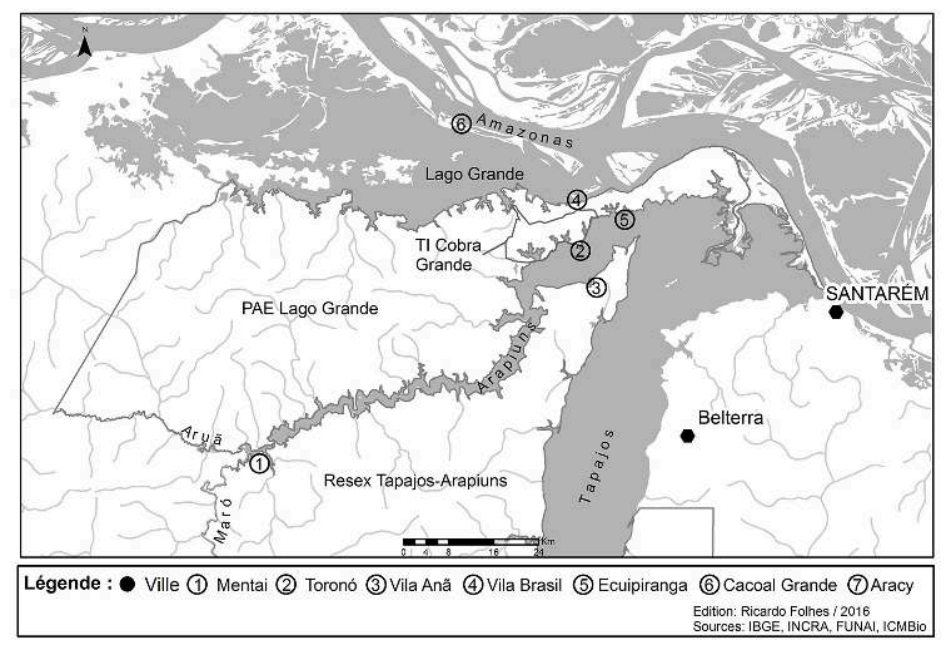

Figure 2

Localisation des lieux cités

(c) Édition : Ricardo Folhes/2016 Sources : IBGE, INCRA, FUNAI, ICMBio

Dans tous les récits, Merandolino est systématiquement localisé en amont de la rivière, à Mentai où il résidait de son vivant, et en aval, sur la pointe de Toronó où il s'est enchanté (figure 2). Mentai est situé à la confluence des deux formateurs de l'Arapiuns, le Maró et l'Aruã. C'est un passage stratégique entre une rivière de large envergure navigable en bateau de ligne (l'Arapiuns) et des cours d'eau plus étroits, ponctués de cascades. En aval de l'Arapiuns, la plage de Toronó est une avancée de sable de plusieurs centaines de mètres qui modifie le lit de la rivière lorsqu'elle apparaît, pendant l'étiage, entre juillet et décembre (figure 3). Le reste du temps, elle est immergée. La nature même de cette plage inondable en fait un élément paysager mouvant, à mi-chemin entre la surface et l'élément aquatique. Les transformations morphologiques que la plage subit d'une crue à l'autre sont autant d'indices sur l'activité de ses habitants subaquatiques et des guérisseurs sacaca qui l'utilisent pour naviguer entre les mondes.

Cette plage du Toronó est aussi un espace stratégique pour la pêche et pour le commerce : passage obligé pour les bateaux de ligne qui relient les villages riverains à la ville de Santarém, la pointe de Toronó est une escale où sont déposés des passagers. D’ailleurs, dans les années 1930, le lieu accueillait même un entrepôt 
commercial (voir récit 2 ci-après). Enfin, la pointe de Toronó fait partie du territoire de la fratrie résidentielle ${ }^{5}$ Barbosa, un groupe de parents installé dans les lieux au moins depuis la première moitié $\mathrm{du} \mathrm{Xx}^{\mathrm{e}}$ siècle. Suite à l'adhésion de cette famille au mouvement indigène, Toronó est devenu une balise spatiale et spirituelle de la terre indigène Cobra Grande.

\section{Des récits de gens ordinaires...}

Pour commencer, je présente deux récits représentatifs de ceux que j'ai fréquemment pu entendre le long de l'Arapiuns. Il s'agit d'énoncés produits par des riverains au cours d'une discussion banale, souvent au sujet d'expériences personnelles liées à la consultation de guérisseurs encore en activité. Mon interlocuteur en venait spontanément à évoquer Merandolino sans que j'aie moi-même orienté la discussion sur ce personnage. Ces récits apportent des éléments généraux sur les prouesses de Merandolino et sur les grandes lignes de sa trajectoire sociale. Le personnage apparaît comme l'exemple type du guérisseur talentueux.

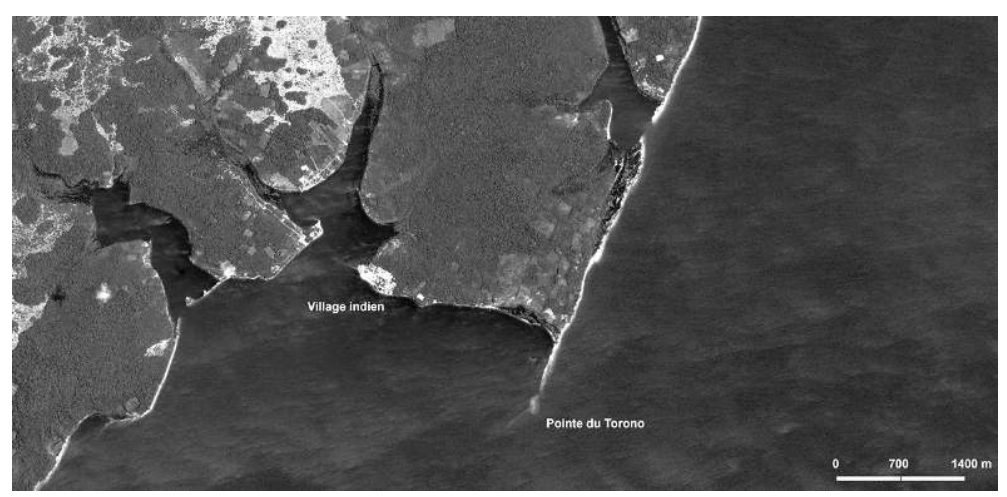

Figure 3

La pointe Toronó pendant l'étiage

Fond de carte: Google Earth / Réalisation: Laurence Billault, IRD

Le premier narrateur, Bruno, habite à Vila Brasil, village légèrement en amont de mon lieu d'étude, sur la rive gauche du bas-Arapiuns. Aucune revendication

5. Le terme « fratrie-résidentielle » (STOLL et Folhes, 2014; STOLL, 2014) renvoie à l'organisation sociospatiale des riverains de l'Arapiuns qui consiste dans l'occupation et dans la transmission, par plusieurs générations de fratries, de territoires aux périmètres fixes. 
identitaire particulière n'est en cours dans cette localité. Bruno a longtemps travaillé comme coordinateur de la chapelle de son village et a officié comme catéchiste dans le bas-Arapiuns (personne en charge des baptêmes en l'absence de prêtre). Il a donc parcouru l'ensemble des villages riverains grâce à ses fonctions ecclésiastiques, mais également en raison de son engagement politique dans les luttes syndicales. Bruno possède ainsi une très bonne connaissance topographique de la géographie locale mais également des réseaux généalogiques et d'interconnaissance distribués le long de la rivière.

Récit 1: «Je n’ai pas connu personnellement Merandolino, mais on m'a raconté son histoire et je connais son petit-fils. Il habite là-bas, un peu après Mentai. Lorsque l'on arrive à l'embranchement entre la Cascade d'Aruã et le Maró [les deux formateurs de l'Arapiuns], alors il y a aussi une pointe appelée Catarina. Sur cette pointe il y a la maison qui appartenait à ce guérisseur célèbre, ce Merandolino. J'ai entendu des histoires à son sujet, il était vraiment très bon. Depuis environ quinze ans, son petit-fils habite là-bas, il s'appelle Salvador. Et il a aussi ce don de guérir, il peut aussi rester sous l'eau plusieurs jours. À chaque fois qu'il y avait des élections, on allait ensemble faire campagne [pour le syndicat] [...]. Les gens racontent que lorsque Merandolino se rendait à Santarém, il avait un grand bateau, les barges à voile (batelão) d'autrefois, alors il envoyait ses employés dans le bateau et lui il restait à Mentai. Et quand les employés arrivaient à Santarém [au bout d'une semaine] parce qu'il n'y avait pas de moteur, lui, il était déjà arrivé ! On dit qu'il s'est enchanté sur la pointe de Toronó. À cet endroit, il se passe des choses bizarres, il y a un tourbillon (rebojo) qui apparaît, et ça, je l'ai vu ; j'ai même eu peur ! J'étais dans le bateau de ligne. Il s'arrête là-bas pour déposer des passagers. J'en avais déjà entendu parler mais je ne l'avais jamais vu. Soudain une femme s'est mise à crier... et j'ai vu... un tourbillon énorme ! Il y avait de l'eau qui jaillissait très haut... Presque aussi haut que cette maison. Le jet expulsait aussi des troncs d'arbre depuis le fond de l'eau. [...] Je l'ai vu de mes propres yeux ! ». Bruno Fonseca, 72 ans, au domicile de l'auteur à Santarém, juillet 2012.

Bruno dresse le portrait-type de Merandolino unanimement connu dans la région, à savoir le guérisseur sacaca qui se déplace sous l'eau à vive allure. Il indique que ce sont des « employés » qui pilotent le bateau du guérisseur jusqu'à Santarém. Pour raconter cette histoire, Bruno précise qu'il possède des sources 
d'information légitimes : d'une part il est un intime du petit-fils du guérisseur défunt, et d'autre part il a lui-même fait l'expérience d'une manifestation de Merandolino sur la pointe de Toronó.

Parmi ces récits ordinaires, certains sont produits par des riverains d'un certain âge qui affirment avoir connu Merandolino de son vivant, dans les années 1930. Ces souvenirs d'enfance consistent toujours en une description physique du guérisseur, suivie d'une anecdote. C'est le cas du récit 2, dont le narrateur, Francisco Godinho, habite actuellement sur la pointe de Toronó, car il a épousé une femme Barbosa. Francisco est né à Vila Anã, un village situé en face de la pointe de Toronó, sur la rive droite de l'Arapiuns. Mais il a été élevé par sa grand-mère à Mentai, dans le haut-Arapiuns. À Vila Anã, les familles Godinho et Guimarães sont majoritaires et liées par la parenté. Leurs membres racontent qu'ils sont le fruit d'un métissage entre une Indienne et un Portugais ${ }^{6}$. Pendant la Cabanagem (un conflit armé du début du $\mathrm{XIX}^{\mathrm{e}}$ siècle), une partie de la famille a fui et s'est réfugiée en amont de la rivière, à Mentai. Certains y résident encore ; c'était le cas de la grand-mère de Francisco. La trajectoire spatiale de cette famille est donc, à l'instar de celle de Merandolino, ancrée en amont (à Mentai) en en aval de la rivière (à Vila Anã, Toronó, etc.).

Récit 2 : « Merandolino était un enfant de la région de Toronó et il s'est marié avec une femme de Mentai. Il faisait beaucoup de prouesses. [...] Je l'ai encore connu [de son vivant] à Mentai. On l'appelle Meroca pour ne pas dire "Merandolino", parce que ça attire les apparitions. Il était grand, corpulent, bien clair, et tout brûlé, comme ces touristes américains qu'on voit parfois. Il est venu une fois avec Monsieur Sarmento, le propriétaire du bateau Sarmento. Il est arrivé à Toronó. Là-bas il faisait du commerce, il y avait un grand entrepôt commercial. L'épouse de mon frère aîné, Lourdes, était sa filleule et c'est lui qui l'a élevée ». Francisco, 73 ans, à son domicile de Toronó, juillet 2012.

Après m'avoir expliqué qu'il a lui-même grandi à Mentai (haut-Arapiuns), Francisco me décrit sa rencontre avec Merandolino, insistant alors sur leur insertion mutuelle dans un même réseau de voisinage, aux alentours de Mentai. Il ajoute qu'avant d'aller vivre sur le terrain de ses beaux-parents, avec son

6. Sur les récits sur l'imaginaire du métissage entre hommes européens et femmes noires ou indiennes dans l'Arapiuns, voir STOLL 2014 et 2015. Pour un autre exemple ailleurs en Amazonie, voir Boyer 2008. 
épouse, Merandolino était lui aussi originaire du bas-Arapiuns (de la « région de Toronó »). Le narrateur insiste sur le phénotype européen de Merandolino, qui avait la peau « bien claire », ce qui le distinguait de la majorité des autres riverains (dont lui), métis, qui ont la peau mate. Il nous informe qu'à l'époque, dans les années 1930, la pointe de Toronó abritait un entrepôt commercial où se rendait le guérisseur pour y faire des affaires. Enfin, Francisco clôt le sujet en laissant entendre que des liens de parenté classificatoire le lient à Merandolino, puisque sa belle-sœur était la filleule et fille adoptive du guérisseur.

\section{... aux motifs d'bistoires extraordinaires}

Comme on peut le voir dans les deux récits ci-dessus, les histoires sur la vie de Merandolino possèdent le style narratif local des histórias (Harris, 2014 ; Slater, 1994) : des récits à la première personne au sujet d'une rencontre insolite avec un non-humain et de l'interaction qui s'en est suivie.

Ainsi, le narrateur est toujours le protagoniste ou l'un de ses proches (quelqu'un de la famille) : Bruno (récit 1) précise qu'il est un intime du petit-fils de Merandolino (dans la version longue, il ajoute d'autres détails sur leur amitié) et qu'il a été témoin en personne d'une manifestation du guérisseur enchanté ; Francisco (récit 2) raconte qu'il a rencontré personnellement Merandolino et que ce dernier était le père adoptif de sa belle-sœur. Dans deux autres versions de cette histoire racontées par le même narrateur, rapportées par Bolaños Cárdenas (2008 : 142) et Mahalem de Lima (2015 : 146), Francisco conte une anecdote sur l'amitié qui liait Merandolino à son beau-père (le père de son épouse Barbosa).

Ces histórias sont ainsi personnelles et relatent systématiquement une rencontre (de visu, auditive, olfactive, etc.) avec un non-humain - un être enchanté subaquatique ou sylvestre - dans un lieu spécifique. Elles attirent un large auditoire et sont commentées et transmises de génération en génération au sein des groupes résidentiels. Elles sont en principe connues de tous mais possèdent des propriétaires légitimes, à savoir les habitants du lieu où se manifestent ces rencontres et apparitions, c'est-à-dire le protagoniste et ses proches parents. La fratrie-résidentielle Barbosa est de cette manière dépositaire de l'histoire de Merandolino-encantado (de par les apparitions à Toronó). Or, comme le remarquait Bolaños Cárdenas à ce sujet, « les Indigènes Arapiuns et Jaraqui [habitants du village où se trouve la pointe de Toronó] m'expriment toujours leur fierté pour ce qu'ils considèrent être leur propre légende. La légende s'est transmise par les histoires que les plus âgés racontent lors de célébrations spéciales et, plus récemment, elle est devenue l'un des thèmes étudiés à l'école [indigène du village] » (2008, p. 43, ma traduction). À travers la mise en « patrimoine » des signes diacritiques d'indianité, depuis l'adhésion de la famille Barbosa et d'autres au mouvement indigène, on observe 
32 Des vies extraordinaires : les territoires du récit $-\mathrm{n}^{\circ} 79$

le glissement d'un savoir propre à un groupe résidentiel à un savoir collectif et institutionnalisé (par l'école) propre à un village indigène (figure 4).

Plus généralement, ces histórias sont un objet de discussion privilégié entre les adultes. Elles sont amplement commentées même si un doute subsiste toujours quant à la véracité des évènements. D’ailleurs, elles peuvent être appelées « histoires de menteurs » lorsqu'elles proviennent d'un chasseur ou d'un pêcheur, narrateurs qui ont souvent tendance à exagérer les faits pour le plaisir de l'auditoire. De manière générale, elles reprennent des motifs très connus en Amazonie, comme celui des encantados et leurs tentatives pour enchanter des humains, ou encore celui de l'embarcation enchantée.

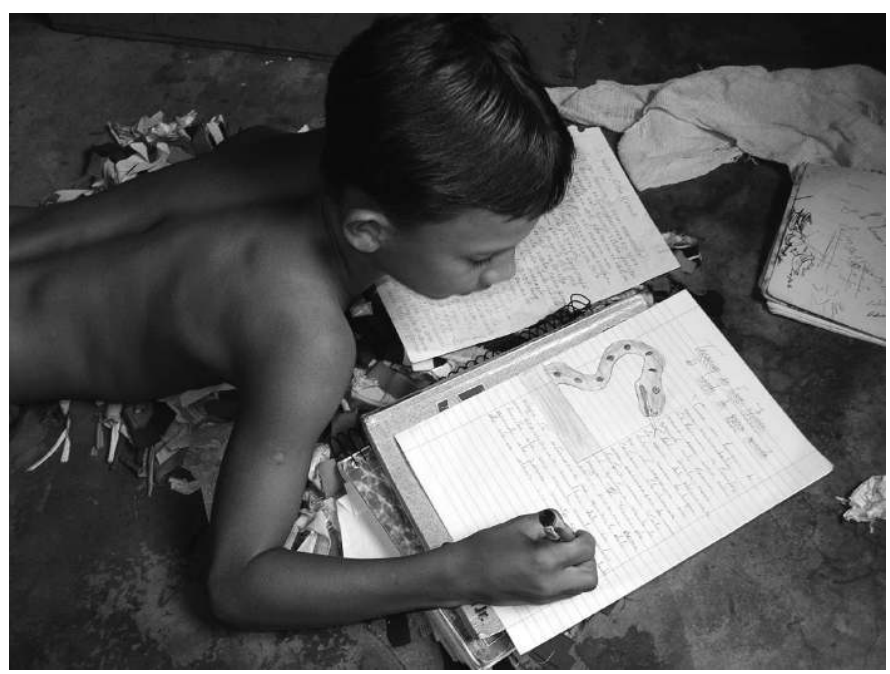

Figure 4

Un écolier de Lago da Praia rédige « la légende du Cobra Grande »

(C) Bolaños Cárdenas, 2008, p. 195 (photo prise le 18 mai 2006)

L'intrigue débute toujours par une rencontre insolite avec un être enchanté puis par la mise en place d'un « champ de communication illusoire » (Taylor, 1993 , p. 434). Parfois le protagoniste humain est leurré par l'apparence humanoïde d'un encantado qui tente de l'enchanter en initiant avec lui une relation commensale ou sexuelle, après l'avoir séduit. D'autres récits relatent une visite de la cité enchantée sur invitation d'un encantado ou d'un guérisseur (figure 5). Le protagoniste est mis en garde de ne pas accepter la nourriture ou les boissons qu'on ne manquerait pas de lui offrir, sous peine d'être enchanté. Le monde enchanté est lié à la pratique d'une forme de « chamanisme aquatique » (appelé localement 
pajelança) qui a pu être décrit comme un «mécanisme cognitif [...] pour penser les déplacements sur de longues distances » le long de la rivière (Chaumeil, 2003, p. 40 ; Gentil et Bruno, 2007, p. 239 et figure 1). Il est éminemment territorialisé.

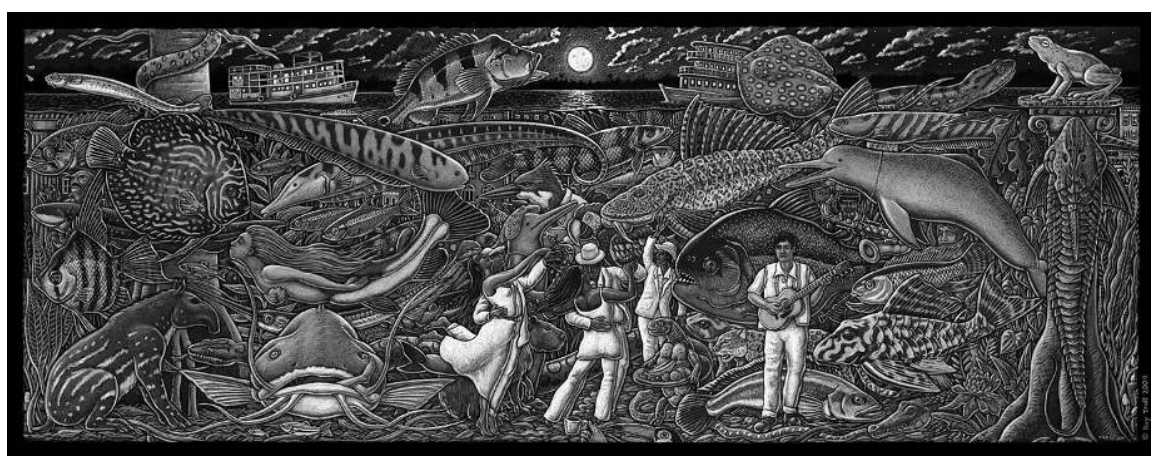

\author{
Figure 5 \\ La cité enchantée \\ (C) Ray Troll, "The Encante”, 2004, colored pencil on paper, 11 x 30" \\ (URL : http://www.trollart.com)
}

Par définition, le pajé sacaca est un être ambivalent, humain et enchanté. Il navigue entre ces deux mondes où il entretient des relations sociales. Comme le disent les riverains, « ces guérisseurs, on dit qu'ils sont mariés sur la terre et dans le monde subaquatique (no fundo) ». Ils ont de ce fait des relations sexuelles et commensales avec des humains et des êtres enchantés. Sur terre, Merandolino était ainsi marié à une femme de Mentai, tandis que « Dolina était sa femme dans la cité enchantée », où se trouve la plage inondable de Toronó. L'autre versant de l'enchantement est la disparition de certains proches, très fréquemment d'enfants (Félix, 2011 ; Stoll, 2014), mais également d'adultes (Faulhaber, 1998, p. 162) et aussi, de guérisseurs décédés (dont le corps disparaît du cercueil). Contrairement au commun des mortels, ce n'est donc que post-mortem que les guérisseurs s'enchantent « pour de bon ». C'est alors un dauphin enchanté qui leur sert de véhicule jusqu'à leur nouvelle demeure (Slater, 1994 ; Dário dans la version longue du récit 3).

Dans ces récits, l'image de l'embarcation - qu'elle prenne la forme d'un Cobra Grande ou d'un bateau, voire d'un dauphin - est récurrente et polysémique (figure 6). La peau d'anaconda de Merandolino est d'ailleurs comparée à une vedette, un bateau à moteur rapide (lancha) que seuls les ONG, la Marine nationale et l'hôpital possèdent (sous forme d'ambulance, l'ambulancha). 


\section{CAHIERS DE LITTÉRATURE ORALE}

34 Des vies extraordinaires : les territoires du récit $-\mathrm{n}^{\circ} 79$

L'embarcation, qu'elle soit enchantée (Cobra Grande, navire enchanté illuminé) ou matérielle (le bateau de ligne ou, à l'époque, la barge à voile), est une sorte de fétiche et est un signe extérieur de richesse (Faulhaber, 1998, p. 154). Or, Merandolino cumule ces embarcations ${ }^{7}$.

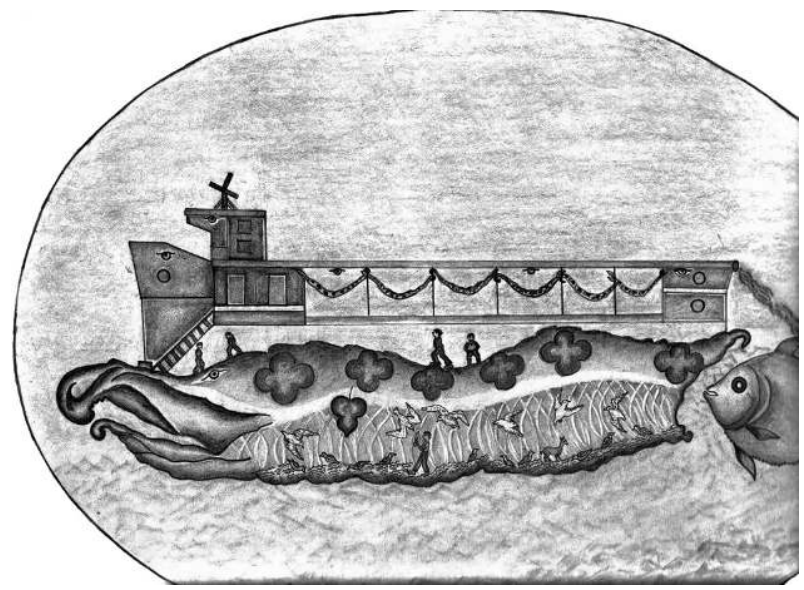

Figure 6

Le serpent aquatique-bateau à vapeur des Indiens Cocama-Cocamilla (C) Rivas Ruiz, 2011, p. 53

L'exploitation de ces différents motifs extraordinaires dans la trame de l'histoire de vie d'une personne réelle - Merandolino - fait ainsi émerger un personnage hors du commun.

7. « Quand [les Indiens] voient [le serpent aquatique], on dit que le grand bateau à vapeur remonte le fleuve. La séance d'ayahuasca terminée, on dit que le serpent, fatigué par sa navigation, s'enfonce et retourne de nouveau dans son nid par la même route et le même tourbillon qui lui a permis d'émerger. Le serpent aquatique reçoit l'appellation wapuru, du castillan vapor, (bateau à) vapeur, car on dit que les chamanes sorciers apparaissent comme des bateaux, leurs corps sont représentés comme les premiers bateaux à vapeur qui autrefois parcouraient les fleuves amazoniens ». (Rivas RuIz, 2011, p. 52-54). 
LA FABRIQUE DES ENTITÉS : RÉCITS SUR L'ENCHANTEMENT D'UN RIVERAIN EXTRAORDINAIRE EN AMAZONIE BRÉSILIENNE

Émilie STOLL

\section{Lorsque le mythe informe les récits des guérisseurs}

\section{Récits de guérisseurs en activité et enchâssement d'épisodes mythiques}

Nous venons de voir que les récits de riverains au sujet de Merandolino reprennent des motifs régionaux que l'on retrouve dans toutes les histoires de rencontre avec des êtres enchantés. Ainsi toutes ces prouesses ne sont pas spécifiques à Merandolino. En revanche, l'accumulation des motifs d'enchantement ainsi que de leur versant matériel (par exemple le bateau) participe à en faire un personnage remarquable et assurément extra-ordinaire. Or, dans des contextes d'énonciation spécifiques, un procédé narratif permet de le hisser au niveau des personnages mythiques ou légendaires. En effet, j'ai interrogé deux spécialistes rituels (des guérisseurs en activité) originaires de la région de l'Arapiuns et ils ont systématiquement inséré un extrait de mythe dans la trame de leur récit. Pour le dire autrement, lorsque les interlocuteurs sont eux-mêmes des individus extraordinaires, le récit de vie de Merandolino intègre un épisode mythique, le propulsant au rang de géniteur des jumeaux mythiques Cobra Norato et Maria Caninana.

Le premier narrateur, Dário, 38 ans, est originaire de São Miguel (Arapiuns) et il habite avec sa famille à Alter do Chão (bas-Tapajós). Ce guérisseur âgé d'une trentaine d'années est spécialiste dans le traitement des afflictions qui touchent les enfants et les nouveau-nés. Nous nous sommes rencontrés dans un restaurant d'Alter do Chão en juillet 2012. Je souhaitais l'interroger sur sa pratique de guérisseur, car il s'était rendu à plusieurs reprises, dans les années 1990, dans le village de l'Arapiuns où je séjournais pour réaliser des rituels de « nettoyage ». Dário était en train de me raconter comment il était devenu guérisseur, après que sa grand-mère sage-femme lui ait transmis son don à sa mort, alors qu'il n'avait que douze ans. Or, c'est pendant qu'il me parlait de sa grand-mère médium qu' il en est venu spontanément à évoquer Merandolino. En effet, sa grand-mère, me disait-il, avait eu un rôle actif dans la naissance des enfants de Merandolino. Je résume ici son récit :

Récit 3 : La grand-mère de Dário était une sage-femme renommée à São Miguel, spécialisée dans les accouchements « difficiles » ou qui sortaient de l'ordinaire ; c'est-à-dire qu'elle était médium et pouvait faire appel à des entités auxiliaires en cas de nécessité (par exemple lorsque le géniteur de l'enfant à naître est un dauphin enchanté ou un guérisseur). La femme de Merandolino attendait des jumeaux et le couple fit appel à la grand-mère de Dário pour l'assister lors de l'accouchement. L'évènement eut lieu une nuit de 
pleine lune, non pas à Mentai, précise Dário, mais à Cacoal Grande [grande plantation de cacao], au bord du lac Lago Grande où Merandolino possédait une seconde résidence. Or, les nouveau-nés avaient la forme de deux serpents enchantés : un garçon et une fille, appelés Norato et Maria Caninana ${ }^{8}$. Ils sont sortis en courant l'un derrière l'autre, et bientôt se sont enfuis de la maison pour gagner la rivière et la cité enchantée, où leur père les a ensuite rejoints. Dário fait alors le lien avec sa pratique de guérisseur actuelle et celle de sa grand-mère, en expliquant qu'il est spécialisé dans la guérison des enfants et des bébés. Quant à Merandolino, qui était le compadre de sa grand-mère ${ }^{9}$, il est le chef de ses entités ; Norato, fils de Merandolino, est également l'un de ses esprits auxiliaires.

Le deuxième récit est celui de José Guimarães ${ }^{10}$, la trentaine, jeune guérisseur originaire et résident d'Araci, un village du Lago Grande, un lac proche de la région de Toronó. Pour s'y rendre, il faut traverser une bande de terre qui sépare la rivière Arapiuns du fleuve Amazone, soit vingt minutes de marche (cf. figure 2). José est membre de la famille Guimarães dispersée entre Vila Anã et Mentai (voir supra). Une ramification a traversé la rivière et l'interfluve Arapiuns-Amazone pour s'installer au bord du lac. Ce narrateur est donc (du moins indirectement) parent avec Francisco, l'auteur du récit 2. J'avais déjà connu José brièvement lors de travaux antérieurs ; aussi l'entretien a-t-il eu lieu une soirée d'août 2012, à mon domicile de Santarém. Il était alors de passage en ville où il prend régulièrement part aux activités d'une maison d'Umbanda (culte de possession afro-brésilien). Je l'ai interrogé au sujet de Merandolino, alors qu' il le mentionnait en passant. Voici ce qu'il me répondit :

Récit 4 : « Merandolino, c'était mon oncle. C'était le frère du grand-père de mon père, donc c'était mon oncle $\gg$. D'après le jeune homme, Merandolino « habitait à l'embouchure (boca) de l'Arapiuns », une zone qui « incluait l'Arapiuns et le Lago Grande ». [Il s'agit de la partie où l'interfluve entre l'Arapiuns et l'Amazone

8. Du nom d'un serpent jaune et noir particulièrement agressif.

9. Le long de l'Arapiuns, une femme qui aide à la naissance d'un enfant est considérée comme sa marraine. Elle devient donc la comadre des parents de son/sa filleul/e. Les personnes cumulent plusieurs parrains et marraines tout au long de leur vie.

10. Nom fictif pour préserver l'identité de mon interlocuteur. 
est le plus mince (voir Figure 2), ce qui permet une circulation entre les habitants du Lago Grande et les riverains de l'Arapiuns]. José ajoute que « Merandolino était un Guimarães comme lui », famille dont les centres de peuplement sont aujourd'hui répartis entre le bas-Arapiuns, Mentai (haut-Arapiuns) et Araci (Lago Grande). Après avoir situé géographiquement la proximité généalogique qui le relie à Merandolino, José passe directement au récit sur les enfants de Merandolino : « Norato a tué sa sœur jumelle, Caninana, qui était méchante et perturbait les hommes. Elle n'épargnait personne et faisait des bêtises au bord de la plage ! ». Il poursuit sur ses activités thérapeutiques. Norato est l'un de ses esprits auxiliaires et « il est toujours vivant. Il s'est enchanté sur une pointe, entre Juruti et Parintins, dans la Boca do Calderão [sic : dans la gueule de la marmite], une entrée entre l'État du Pará et l'État de l'Amazonas ». José clôt son récit en affirmant que son don de guérisseur lui a été transmis par « le sang de son père » et que c'est donc de cet ascendant collatéral, Merandolino, qu'il l'a reçu en héritage.

Ces deux récits de guérisseurs avec lesquels je n'étais pas intime ont de nombreux points communs. Dans les deux cas, il s'agit de récits à visée légitimatrice qui sont servis à l'ethnologue comme une preuve de crédibilité de leurs activités thérapeutiques. On y retrouve le style de l'história avec la volonté de tracer un lien de parenté avec une source légitime : la grand-mère protagoniste de l'histoire (récit 3) et une histoire de famille (récit 4). Les deux guérisseurs donnent également un ensemble de détails spatiaux et sociaux au sujet de Merandolino. Il est présenté comme ayant une double résidence, à Mentai et Cacoal Grande (récit 3), et comme un résident de l'embouchure de l'Arapiuns, à mi-chemin avec le Lago Grande, où se trouve une partie de la famille dont il est supposé être issu (récit 4); on retrouve donc une fois de plus cette trajectoire spatiale entre l'amont et l'aval à laquelle vient s'ajouter un mouvement transversal entre l'Arapiuns et le Lago Grande. Ces descriptions de lieux donnent des indices sur la condition sociale de Merandolino, propriétaire d'une maison dans les plantations de cacao et possédant des liens avec les habitants du Lago Grande, une terre plus riche que celle de l'Arapiuns (voir ci-après et Stoll 2014). Enfin et surtout, ce qu'apportent ces récits sont des détails sur la progéniture de Merandolino, décrite comme des anacondas enchantés. Or, il s'agit ici d'une version du mythe de Cobra Honorato, amplement connu dans toute l'Amazonie brésilienne riveraine métisse. 
CAHIERS DE LITTÉRATURE ORALE

38 Des vies extraordinaires : les territoires du récit $-\mathrm{n}^{\circ} 79$

\section{Le mythe de Cobra Honorato}

Qu'ils viennent de la région du Salgado sur le littoral (Maués, 1995), de la région du Trombetas (Sauma, 2013) ou de la rivière Solimões (Faulhaber, 1998), les riverains racontent des versions du mythe de Cobra Honorato ${ }^{11}$. La trame est toujours la même, ce qui change sont les noms des lieux, certains épisodes de la dispute entre les jumeaux et la façon dont Honorato est désenchanté. Voici en quelques traits son contenu :

Une jeune femme, décrite comme indienne ou métisse (tapuia, cabocla), tombe enceinte d'un anaconda géant - Cobra Grande ou Boiúna, Boiaçú (grand serpent en nheengatú) - après s'être baignée dans la rivière. Elle met au monde des jumeaux, un garçon et une fille, qui sont des serpents. Elle les baptise Honorato (ou Norato) et Maria Caninana et les jette dans la rivière, parfois sur les conseils d'un pajé. Les serpents grandissent et deviennent deux anacondas géants. Le garçon, Honorato, est gentil, attentionné et sociable. Il vient régulièrement rendre visite à sa mère, il sauve les hommes lorsque leur barque chavire, etc. Il aime se rendre aux bals des riverains : il laisse alors sa peau d'anaconda au bord de l'eau et se transforme en beau jeune homme clair vêtu de blanc pour aller danser. Sa sœur est son contraire. Elle est méchante et asociale. Elle ne rend jamais visite à sa mère et passe son temps à couler les bateaux, tuer les pêcheurs et les animaux aquatiques, etc. Dans certaines variantes, Maria Caninana tente de couler la ville d'Óbidos $^{12}$ (Slater, 1994, p. 155) ou d'en faire tomber l'église en mordant un autre anaconda qui s'y trouve (Cascudo, 2001, p. 29 ; figure 7). Mais son frère s'interpose et leur lutte serait à l'origine de la grande fissure que l'on peut voir jusqu'à aujourd' hui sur le perron de l'église. Finalement, Honorato décide de tuer sa sœur pour mettre fin à ses méchancetés. Dans une variante du Salgado, il la tue car il s'oppose à son mariage avec un autre serpent enchanté ; cette union aurait rendu impossible son propre désenchantement (Maués, 1995). Une fois sa sœur morte, Honorato n'a qu'une idée en tête : se désenchanter pour aller vivre dans le monde des hommes. Il y parviendra finalement après une longue quête car avant lui tous ceux qui s'y étaient essayés avaient échoué pour avoir pris peur à la vue de l'anaconda monstrueux. Les versions diffèrent sur la forme que prend cet épisode.

11. On peut considérer que le mythe de Cobra Honorato est lui-même une variante ou un épisode du mythe plus général de Cobra Grande (voir TASTEvin, 1925 ; TipHagne, 2005, p. 117).

12. Cette histoire est racontée de la même façon en ce qui concerne la cathédrale de Nossa Senhora do Rosário, dans la ville d'Itacoatiara (Amazonas). 
Pour certains (sans doute la version la plus répandue), c'est un soldat d'Óbidos qui le désenchante en lui crevant un œil par mégarde (Slater, 1994, p. 122). Dans d'autres versions, c'est sa propre mère qui s'en charge. Dans le Salgado, une autre version circule au sujet du combat entre Cobra Honorato et un autre anaconda enchanté, le Roi Sébastien, un encantado de l'île de Manindeua (littoral atlantique). Ce dernier gagne le combat et tue Honorato, devenant ainsi le roi des encantados d'Amazonie (Maués, 1995). Les riverains d'Erepecuru relatent que suite à la défaite de la sœur, les os des côtes du serpent servent de support à l'autel de la statue de Notre Dame de Nazareth dans la basilique de Belém, capitale du Pará (Sauma, 2013, p. 71).

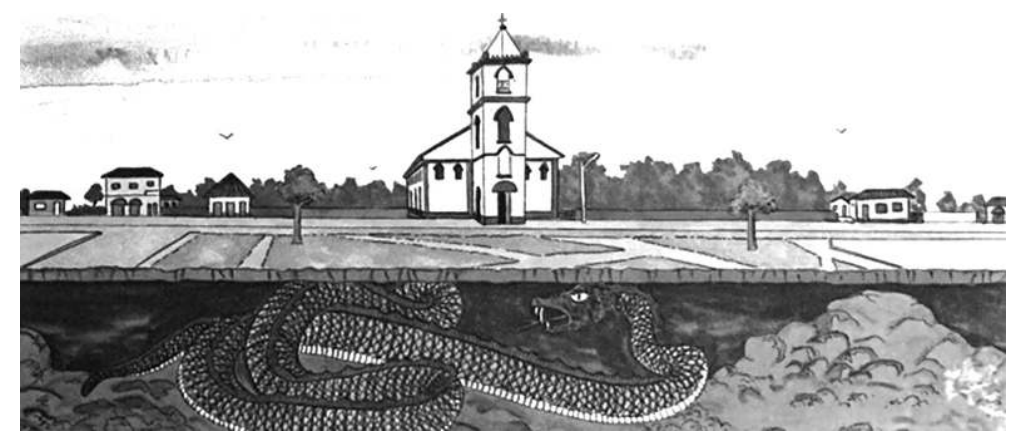

Figure 7

L'anaconda géant de la cathédrale d'Itacoatiara, mordu par Caninana

(C) No Amazonas é assim - Blog brésilien sur la culture amazonienne (source : http://noamazonaseassim.com.br/a-lenda-da-cobra-grande-debaixo-da-catedralde-itacoatiara/ )

Dans la version mythique, ni les lieux ni la mère des jumeaux ne sont identifiés, ce qui permet une appropriation de cette histoire par tout un chacun. Dès lors, les différentes versions mettent en scène divers personnages : une Indienne du Tocantins ou du Solimões, une tapuia du Trombetas ou d'Erepecurú, une cabocla de la rivière Paru et... la femme de Merandolino dans l'Arapiuns ! La trame du mythe informe ainsi le récit des guérisseurs Dário et José sur la vie et la naissance des enfants de Merandolino. Ce procédé permet de rattacher ce personnage qui a réellement vécu à un panthéon mythique d'entités auxiliaires, admettant sa pérennisation sous une forme spirituelle. 
CAHIERS DE LITTÉRATURE ORALE

40 Des vies extraordinaires : les territoires du récit $-\mathrm{n}^{\circ} 79$

\section{Jumeaux-animaux enchantés, production et reproduction des pajés}

Il faut savoir que les récits sur la naissance de jumeaux enchantés dans des conditions similaires à celles décrites dans le mythe sont finalement chose courante dans le bas-Amazone (Galvão, 1976, p. 70 ; Slater, 1994, p. 99 ; Stoll, 2014, p. 239). En général, il s'agit de petits du Boto (botinhos), ce dauphin rose enchanté qui prend l'apparence d'un beau jeune homme blond vêtu de blanc et qui séduit et met enceinte les riveraines lors des fêtes dansantes. L'analogie de ce personnage avec Cobra Honorato est frappante et a aussi été relevée par Slater (1994, p. 114).

Dans l'Arapiuns, des femmes affirment avoir mis au monde des enfants qui avaient la forme d'animaux, principalement de dauphins, mais également de raies, voire d'hybrides (par exemple un bébé sirène). Dans les récits les plus détaillés auxquels j'ai eu accès, il s'agissait de jumeaux : l'un était un bébé humain, l'autre un petit du Boto. Le jumeau enchanté est jeté dans la rivière tandis que le petit humain, s'il survit à l'accouchement, développe un don médiumnique qui le destine à devenir guérisseur. De cette manière, l'accouplement entre une femme et un encantado (qu'il soit Cobra Grande, Boto ou autre) crée de nouveaux êtres enchantés - puisque le bébé enchanté est rendu au monde subaquatique - ainsi que la production de guérisseurs au sein du collectif humain. Cette hypothèse semble confirmée par Zeneida Lima, une guérisseuse notoire de l'île de Marajó (estuaire de l'Amazone). Dans un livre autobiographique, elle explique que son don de guérisseuse est lié à « une chose jumelle » née avec elle, qui avait « une forme ronde, totalement enveloppée par la poche de liquide amniotique et qui avait des yeux, un nez, une bouche et tous les organes $\gg$ (Lima, 1993, p. 54, ma traduction). Merandolino est quant à lui le père de Cobra Honorato, qui finit éventuellement par devenir humain et officier à son tour comme guérisseur auprès des riverains. Dans ces récits, la gémellité assure ainsi la production et la reproduction des grands sacacas. Il n'est donc pas étonnant que lorsque les narrateurs sont des guérisseurs qui produisent des récits institutionnalisés, l'histoire de Merandolino soit associée à cette théorie native sur la production du don de médiumnité.

\section{Pour une sociologie du mythe}

\section{Une topographie des réseaux d'interconnaissance et des lieux saillants}

Nous sommes en présence de procédés langagiers visant à faire de Merandolino un personnage légendaire voire mythique. Or, cette uniformisation de son histoire, à travers des récits-types et une trame mythique, ne se fait pas au détriment des détails sociologiques de l'affaire. On a au contraire une personnalisation marquée 
du personnage, avec son inscription dans des lieux précis, dans une parentèle spécifique et dans un milieu social déterminé. En effet, les histoires fourmillent de détails sociologiques, qu'elles aient pour auteurs des riverains ordinaires ou des guérisseurs.

Les récits retracent l'itinéraire d'un riverain originaire d'une famille du bas-Arapiuns, de la « région de Toronó », où la circulation avec le Lago Grande se fait poreuse. On voit en effet que certains groupes familiaux, comme celui des Guimarães dont sont issus les narrateurs des récits 2 et 4 , et dont il est dit que Merandolino ferait partie (récit 4), ont développé des stratégies d'occupation régionale selon deux axes : un axe transversal entre la rive droite de l'Arapiuns et le Lago Grande, et un axe riverain entre l'amont et l'aval de l'Arapiuns. Suite à son mariage avec une native du haut Arapiuns, Merandolino s'établit sur le terrain de ses beaux-parents, dans les environs de Mentai. En effet, dans l'Arapiuns, on observe une tendance à l'uxorilocalité, sans que cela soit la règle. En revanche, en pratique, les riverains perdent leurs droits sur la terre de leurs parents à partir du moment où ils s'installent sur celle de leurs beaux-parents. Ceci n'empêche pas les membres d'une fratrie de négocier entre eux l'accès aux ressources du terrain parental (Stoll, 2014), par exemple pour cultiver le cacao ou ponctionner d'autres produits. C'est sans doute sous cette forme que l'on prête à Merandolino des activités en aval de la rivière (dans un entrepôt commercial à Toronó, dans une plantation de cacao, etc.), quand bien même il réside à Mentai. D'ailleurs, ce n'est qu'une fois enchanté que la pointe de Toronó devient sa maison.

Or, cette famille Guimarães, dont on voit qu'elle domine des espaces stratégiques le long de la rivière (l'amont, l'aval et le Lago Grande) possède une histoire singulière. Les descendants affirment être issus d'un mariage entre une Indienne et un Portugais. Et il se trouve que l'histoire confirme cette version puisque les Guimarães de Santarém sont issus d'une des plus anciennes familles de Portugais à s'être installées à Santarém pendant l'époque coloniale. L'un des personnages illustres de la famille, Miguel Antônio Pinto Guimarães Junior (1808-1882), a été anobli Baron de Santarém et a occupé des fonctions politiques élevées. Le Baron possédait des terres dans la zone rurale d'Ituqui, mais on peut imaginer qu'un de ses descendants se soit installé à Anã, à proximité de Vila Franca, ancienne mission jésuite et bourgade d'importante envergure jusqu' au début du XIX ${ }^{\mathrm{e}}$ siècle, où résidaient de nombreux « Blancs ${ }^{13}$ éleveurs et cultivateurs de cacao.

13. Il s'agit d'un terme local, utilisé pour désigner des descendants d'Européens présumés. 
CAHIERS DE LITTÉRATURE ORALE

Des vies extraordinaires : les territoires du récit $-\mathrm{n}^{\circ} 79$

\section{Un commerçant nanti du début du XX $x^{e}$ siècle?}

Les détails sur la topographie généalogique et spatiale de la trajectoire de Merandolino sont accompagnés d'indices sur sa position sociale plutôt élevée. En effet, tous les récits décrivent qu'il possédait un bateau et pas des moindres. Il s'agissait d'une barge à voile (batelão), ce que peu de riverains pouvaient se vanter de posséder. Dans le récit que Francisco (narrateur du récit 2) fait à Lima, il donne plus de détails à ce sujet :

À cette époque, il y avait très peu de bateaux dans l'Arapiuns, « une personne avait une bijarrona, une embarcation à trois voiles », et quelques autres avaient « un batelão à deux voiles ». La plupart avaient seulement des barques ou des canoës, il fallait ramer, et on ne pouvait se déplacer que sur de petites distances. Mirandolino était le seul qui avait un grand bateau à moteur très beau et tout illuminé (Mahalem de Lima, 2015, p. 145, ma traduction).

L'anecdote insiste donc sur le bateau hors du commun et assurément unique de Merandolino, qui était «à moteur et tout illuminé ». La description fait penser à un bateau de ligne, ce qui expliquerait les « employés » mentionnés dans le récit 1 . Il fait le pont avec le motif du navire enchanté, une embarcation qui apparaît la nuit, toute illuminée avec des bruits de fête.

Les récits décrivent souvent Merandolino alors qu'il effectue un voyage à Santarém, enroulé dans sa peau d'anaconda. Il est en effet présenté comme un commerçant. Il fait des affaires à Santarém, mais également à l'entrepôt commercial de la pointe de Toronó (récit 3). Il a des gens à son service (les « employés » du récit 1 ). Apparemment, il possédait lui-même « une taverne bien achalandée » à Mentai (Mahalem de Lima, 2015, p. 145), localité stratégique pour installer un commerce puisque c'est un passage obligé pour se rendre dans l'Aruã et le Maró. On retrouve également cette conception du sacaca-commerçant dans le Solimões, où les riverains racontent qu'après avoir été désenchanté, Cobra Honorato est « devenu un Blanc ou un caboclo [métis] »; certains affirment même « qu'il est marreteiro (commerçant [navigant]) »(Faulhaber, 1998, p. 169). Ainsi, en arrière-plan des récits sur l'enchantement de Merandolino se dessine un riverain intégré à la vie économique régionale, un commerçant qui opère le long de la rivière, sans doute actif dans les réseaux d'aviamento (forme traditionnelle de crédit à la base du système de production des produits d'extraction, comme le caoutchouc ; voir Santos, 1968), avec ses fournisseurs et ses clients. 


\section{Perception du métissage et bétérogénéité régionale}

En toile de fond de cette accumulation de détails se dégage assez nettement une conclusion : Merandolino, pajé sacaca, était par ailleurs un «Blanc $»$; descendant de Portugais, propriétaire de bateau et commerçant. C'est ce que confirme Francisco (récit 2) lorsqu'il décrit son phénotype : «blond, clair, à la peau brûlée comme celle des touristes américains ».

La mention de Cacoal Grande comme l'un des lieux d'activité de Merandolino (récit 3) fait explicitement référence à la culture du cacao dans les plaines inondables du Lago Grande, une activité économique mise en place par les Européens à l'époque coloniale. Ces plantations avaient recours à de la main-d'œuvre esclave, noire et indigène. La configuration géographique était telle que la plupart des colons européens occupaient le Lago Grande tandis que l'Arapiuns est jusqu'à aujourd' hui référé comme la terre des pauvres (Noirs et Indiens). Or, dans la région de Toronó, où l'interfluve entre l'Arapiuns et l'Amazone est étroit (figure 2), de nombreuses familles du Lago Grande se sont installées au bord de l'Arapiuns, afin de bénéficier du double écosystème, plus commode pour l'élevage bovin ou encore pour diversifier leurs activités productives. Les indices convergent de façon à laisser penser que la trajectoire de Merandolino est celle de l'un de ces « Blancs », à mi-chemin entre ces deux univers.

Mahalem de Lima (2015, p. 102) propose une hypothèse allant dans le même sens. Selon lui, Merandolino était parent avec un propriétaire terrien de Cuipiranga, maître d'esclaves et possédant une ferme à Mentai. Toujours selon cet auteur, pendant la deuxième moitié du XIX ${ }^{\mathrm{e}}$ siècle, Merandolino aurait acquis le terrain de Cuipiranga (par héritage ?) puis l'aurait vendu en 1908 alors qu'il s'installait à Mentai (chez son épouse). Cette hypothèse doit être vérifiée et si elle s'avérait exacte, Merandolino ne serait donc pas issu (sinon par alliance) de la famille Guimarães comme annoncé dans le récit 4. Malgré tout, on reste sur le même profil d'individu et sur une trajectoire sociale semblable. J'ajouterai qu'à la fin de mon entretien avec José Guimarães (récit 4), je lui ai proposé que nous fassions ensemble son arbre généalogique, ce à quoi il s'est dérobé, prétextant que ses entités auxiliaires ne lui en avaient pas donné l'autorisation.

La trajectoire de Merandolino est donc un bon exemple de la façon dont les riverains accommodent une classification dichotomique des populations régionales (Blancs versus pauvres, Noirs, Indiens) ancrée dans l'espace (Lago Grande versus Arapiuns) à des pratiques d'occupation spatiale perméables à ces deux espaces. La disposition réticulaire des familles et de leurs lieux d'habitation, au gré des alliances matrimoniales, selon deux axes (transversal à l'interfluve et riverain) n'occulte ainsi pas les distinctions sociales. De cette façon, suite à son mariage 
avec une riveraine de Mentai, Merandolino déplace sa qualité de « Blanc » dans ce lieu ; de même qu'ont pu le faire avant lui les Guimarães d'Anã. On voit comment ces récits décrivent un espace hétérogène où circulent des hommes, des entités mais également des écarts différentiels, aménageables à loisir. Par exemple, la famille Barbosa, dont on peut supposer qu'elle possédait aussi le profil des «Blancs » (entrepôt commercial, amitié avec Merandolino, etc.), a récemment choisi de s'identifier à une ascendante indienne « attrapée au lasso », et de faire de Merandolino un emblème identitaire dans son autoaffirmation indigène.

Chanson « Merandolino », composée et interprétée par Seu Nezinho Raimundo Branches de Sousa, cacique d'Arimum, terre indigène Cobra Grande, Santarém - Pará. (https://clo.revues.org/2792)

\section{Conclusion}

Dans cet article, j'ai voulu montrer à partir de l'histoire de Merandolino comment peut se former une légende au sujet d'une personne hors du commun, grâce à un procédé stylistique qui vise à enchâsser dans la narration d'anecdotes personnelles des motifs extraordinaires et, dans certains contextes spécifiques, des épisodes mythiques. Or, cette façon particulière de procéder - un mythe qui informe des récits de vie - n'est pas circonscrite à l'Arapiuns ni au cas de Merandolino. Ailleurs dans le bas-Amazone, à Parintins, Slater (1994, p. 131, 148) a relevé une occurrence similaire, au sujet d'un pajé sacaca appelé Munju ${ }^{14}$. D'après cet auteur, Munju est identifié par certains interlocuteurs ${ }^{15}$ comme le père de jumeaux anacondas, dont l'un d'entre eux est Cobra Norato. L'histoire se termine par une variante qui met en scène une dispute entre les anacondas et leur père. Munju finit par se faire dévorer par ses propres enfants.

Dans la littérature ethnographique, on trouve quelques autres exemples d'insertion de récits mythiques dans des anecdotes vécues : c'est le cas d'un chamane amérindien du Xingu, au Brésil, qui raconte ses rêves à l'anthropologue, ceux-ci étant des épisodes de mythes xinguanos (Patrick Menget, communication personnelle). Dans les Andes péruviennes, Robin Azevedo (2008, p. 141-178) donne également des exemples d'enchâssement de contenus stéréotypés qui se rapprochent du mythe (les histoires de damnés) dans des récits au sujet d'évènements réels

14. Terme en nheengatú désignant une substance enchantée (Renato Athias, communication personnelle).

15. Slater ne précise pas si ses interlocuteurs sont des guérisseurs. 
liés à des morts violentes (souvent suite à des actions de guérilla), ce qui permet d'actualiser ces faits dans un registre plus conventionnel.

Dans le bas-Amazone, on peut se demander si ce procédé langagier très particulier, et dont on voit qu'il est utilisé par des guérisseurs pour parler d'un confrère décédé devenu l'un de leurs esprits auxiliaires, ne serait pas localement la façon par laquelle sont créées de nouvelles entités de la pajelança, comme le sont déjà Norato, le Roi Sébastien et bien d'autres. Plus de soixante-dix ans se sont écoulés depuis le décès de Merandolino et il semblerait que son statut soit en train d'évoluer. Des indices vont dans le sens de cette transition, du personnage historique au héros légendaire, pour finalement devenir un esprit auxiliaire des guérisseurs de la région, qu' ils soient ou non de l'Arapiuns. Ceci expliquerait une certaine divergence parmi les riverains au sujet de la nature de Merandolino : si tous s'accordent sur son enchantement à Toronó, seuls certains conçoivent qu'il soit une entité susceptible d'être invoquée dans le cadre des rituels de possession. Du point de vue des guérisseurs, en revanche, ce passage est déjà effectif et il est probable que d'ici quelques années, cet encantado et son histoire auront intégré les cultes de possession urbains et ruraux de toute la région, voire au-delà. L'exemple de Merandolino expose ainsi de façon assez convaincante comment un procédé narratif (l'enchâssement d'un mythe dans un récit de vie) participe à « fabriquer » une nouvelle entité. L'occurrence d'un procédé similaire rapporté par Slater (1994), tout comme la diversité foisonnante et créative des entités invoquées dans les rituels de pajelança ou dans les cultes urbains de possession afro-brésiliens, semblent indiquer que cette pratique est répandue dans l'univers riverain amazonien.

Or, dans les deux cas ethnographiés - Munju à Parintins et Merandolino dans l'Arapiuns -, il semble que l'identité sociale des protagonistes ne soit jamais effacée au profit de leur changement de statut, d'une personne de chair à un personnage mythique ou légendaire. On sait grâce à l'exemple de Merandolino que cette identité sociale est même minutieusement décrite et remémorée. Ceci pose un certain nombre de questions en lien avec la sociologie du mythe. Nous avons vu que Merandolino est décrit comme un commerçant nanti, descendant de Portugais. Il cumule l'aspect spirituel et matériel des motifs véhiculés par le monde enchanté (bateau, pouvoir d'articulation, etc.). Cet aspect fondamental a participé à faire de lui un individu remarquable et éligible à l'enchantement dans un lieu saillant de par sa configuration paysagère et commerciale. Est-ce à dire, alors, que la fabrique de l'entité Merandolino, avec son histoire riche de détails sociologiques, est aussi une manière de pérenniser la présence régionale de certaines figures de «Blancs »?

Dans ses travaux pionniers sur la structure du mythe, Lévi-Strauss évoquait déjà la ressemblance entre la «pensée mythique » et « l'idéologie politique », 
dans le sens où toutes deux partent de récits d'évènements passés pour inférer des structures sociales présentes. Il prend alors l'exemple d'un évènement historique - la Révolution française - pour montrer que l'évocation actuelle de cette référence doit être comprise comme « un schème doué d'une efficacité permanente, permettant d'interpréter la structure sociale de la France actuelle » (Lévi-Strauss, 1955, \$9). Cette analyse semble pertinente pour l'exemple qui nous occupe. Si l'on y pense, la plupart des encantados sont décrits sous des traits physiques vus comme caractérisant les Européens. Ils portent même parfois des noms significatifs, comme « Germano » (au sujet d'un « allemand enchanté »), soit autant de marqueurs mémoriels au sujet du passé colonial marqué par des flux migratoires vers l'Amazonie et de l'inévitable métissage qui s'en est suivi. Un autre exemple de cette réactualisation du passé dans le présent est celui du Roi Sébastien. Sous sa forme humanoïde, il est décrit comme Blanc et blond ${ }^{16}$, et son histoire est celle de Sébastien I ${ }^{\text {er }}$ du Portugal, disparu (enchanté) au combat lors d'une bataille au Maroc (Alcacer-Kebir, en 1578) ${ }^{17}$. D'autres personnages au statut social élevé co-résident avec le Roi Sébastien, comme le roi des Turcs (enchanté lors d'une croisade à Jérusalem), ou encore le roi Camutá de Hollande (corsaire hollandais qui a coulé au large des côtes du Maranhão).

Ces exemples posent la question du statut des grands guérisseurs : une bonne condition sociale est-elle indispensable dans le fait de devenir un être enchanté pour la postérité ? Une chose est sûre, tout semble indiquer que le cumul d'une super-agentivité spirituelle et matérielle concoure à produire les conditions propices à la naissance d'une nouvelle entité.

\section{Bibliographie}

Bolaños Cárdenas, Omaira, 2008, Constructing Indigenous Ethnicities and Claiming Land Rights in the Lower Tapajos and Arapiuns Region, Brazilian Amazon, PhD, Gainesville, University of Florida.

16. Le nombre important d'albinos qu'on trouve dans cette île est corrélé à une paternité de Sébastien.

17. Une littérature abondante existe sur le sébastianisme (par ex. Valensi, 1992), un mythe messianique portugais qui consiste à espérer le retour sur le trône du Portugal du jeune roi Sébastien I, disparu lors de la bataille des Trois Rois (à Alcacer-Kebir), dont la légende rapporte qu'il ne serait pas mort. 
Boyer, Véronique, 2008, "Passado português, presente Negro e indizibilidade ameríndia: o caso de Mazagão Velho, Amapá”, Religião e Sociedade (Rio de Janeiro), vol. 28, $\mathrm{n}^{\circ}$ 2, p. 11-29.

Cascudo, Luís da Câmara, 2001 [1945], Lendas brasileiras, São Paulo, Global ed.

Chaumeil, Jean-Pierre, 2003, “Ciudades encantados y mapas submarinos. Redes transnacionales y chamanismo de frontera en el Trapecio Amazónico”, in : F. Morin et R. SANTANA, Lo transnacional: instrumento y desafio para los pueblos indigenas, 2 ed., Quito, Abya Yala, p. 25-50.

Faulhaber, Priscila, 1998, O Lago dos Espelhos: etnografia do saber sobre a fronteira em Tefé/Amazonas, Belém, MPEG.

FÉLIX, Camila Corrêa, 2011, Sentidos da ação: proteção e perigo numa comunidade remanescente de Quilombo do Rio Trombetas, Mestrado, Rio de Janeiro, UFRJ/ PPGAS.

Galvão, Eduardo, 1976 [1955], Santos e visagens: um estudo da vida religiosa de Itá, Baixo Amazonas, $2^{\mathrm{e}}$ ed., São Paulo, Nacional.

Gentil, Gabriel, “A casa de danças”. Présentation de Ana Carla Bruno, História, Ciência, Saúde - Manguinhos, v. 14, suplemente, 2007, p. 213-255.

Harris, Mark, 2014, "Seeing through the Smoke: the Invisible World amongst Ribeirinhos of the Brazilian Amazon”, manuscrit.

LÉvi-Strauss, Claude, 1955, « la Structure des mythes », texte annoté et traduit par Elizabeth Benware, d'après l'article original "The Structural Study of Myth”, in "Myth, a Symposium”, Journal of American Folklore, vol. 78, no. 270, 1955, pp. 428-444. URL : http://litgloss.buffalo.edu/levistrauss/text.shtml consultée le 12/10/2015.

Lima, Zeneida, 1993, O mundo mistico dos Caruanas e a revolta da sua ave, Belém, CEJUP.

Mahalem de Lima, Leandro, 2015, No Arapiuns, entre verdadeiros e - ranas. Sobre as lógicas, as organizações e os movimentos dos espaços do político, Thèse de doctorat, São Paulo, USP. 
CAHIERS DE LITTÉRATURE ORALE

Des vies extraordinaires : les territoires du récit $-\mathrm{n}^{\circ} 79$

Maués, Raymundo Heraldo, 1995, Padres, Pajés, Santos e Festas : catolicismo popular e controle eclesiástico, Belém, CEJUP.

Rivas Ruiz, Roxani, 2011, le Serpent, mère de l'eau. Chamanisme aquatique chez les Cocama-Cocamilla d'Amazonie péruvienne, Thèse de doctorat, Paris, EHESS.

Robin Azevedo, Valérie, 2008, Miroirs de l'autre vie. Pratiques rituelles et discours sur les morts dans les Andes de Cuzco (Pérou), Paris, Société d'ethnologie.

Santos, Roberto A. O., 1968, "O equilíbrio da firma aviadora e a significação econômico-institucional do aviamento”, Pará Desenvolvimento, vol. 3, p. 9-30.

Sauma, Julia, 2013, The Deep and the Erepecuru: Tracing Transgressions in an Amazonian Quilombola Territory, PhD, London, University College London.

Slater, Candace, 1994, Dance of the Dolphin: Transformation and Disenchantment in the Amazonian Imagination, Chicago \& London, The University of Chicago Press.

STOLL, Émilie, 2014, Rivalités riveraines : territoires, stratégies familiales et sorcellerie en Amazonie brésilienne, Thèse de doctorat, Paris, EPHE.

STOLL, Émilie, 2015, « Montrer l'autre pour dire le soi, montrer le soi pour dire l'autre : la "Farce des Nègres" du bas-Tapajós (Amazonie brésilienne) », Gradhiva, n' 22, p. 158-184.

Stoll, Émilie et Folmes, Ricardo T., 2014, « La (dés)illusion communautaire : de l'ambivalence de la notion de "communauté" en Amazonie brésilienne », Journal de la Société des Américanistes, tome 100, n² 2, p. 73-103.

Tastevin, Constant, 1925, « La légende de Boyusu en Amazonie », Revue d'ethnographie et des traditions populaires, vol. 22, p. 172-206.

TAYLOR, Anne-Christine, 1993, « Des fantômes stupéfiants : langage et croyance dans la pensée Achuar », l'Homme, vol. 33, nº 126-128, p. 429-447.

Tiphagne, Nicolas, 2005, Entre nature et culture, les enchantements et les métamorphoses dans le monde caboclo de l'Est de l'île de Marajó : invention et discours sur l'autre, prémisse d'une identité, Thèse de doctorat, Paris, Université Paris 7 Diderot. 
Valensi, Lucette, 1992, Fables de la mémoire. La glorieuse bataille des Trois Rois, Paris, Seuil.

Résumé : Le mythe de Cobra Honorato, largement diffusé en Amazonie brésilienne sous de multiples variantes, met en scène un serpent enchanté (encantado) et sa sœur jumelle, fruits de l'union charnelle entre une femme et une entité subaquatique. Dans la zone rurale de Santarém, bas-Amazone, cette trame narrative informe de façon récurrente les récits produits sur les trajectoires de vie d'individus remarquables (comme de grands guérisseurs décédés). À travers ces récits, les riverains retracent un réseau d'interconnaissance fondé sur la parenté en insistant sur ses dimensions spatiale, historique et sociologique. Je montrerai par ailleurs comment ces actualisations du mythe servent des enjeux microsociologiques, et permettent d'appréhender les conditions historiques des jeux de pouvoir et de domination au sein de la population régionale.

Mots clefs : encantados, Cobra Honorato, gémellité, récit de vie extraordinaire, Brésil, Amazonie, ethnologie

\section{Making New Entities: Narratives about the Enchantment of an Extraordinary Man in the Brazilian Amazon}

Abstract: Cobra Honorato myth is widely spread in the Brazilian Amazon. Although the story may include multiple versions, it is mainly about the adventures of twin children born from the intercourse between a woman and a subaquatic being. As a consequence, Honorato and his sister were born in the shape of giant anaconda snakes. In Santarém rural area (Lower Amazon), this story informs the narratives about the life and trajectory of remarkable people (such as deceased healers). While they recount these stories, the riverine peasants of the Amazon reconstitute a meshwork based on kinship, insisting on its spatial, historical and sociological aspects. I will demonstrate how such actualisations of this specific mythic story attend to micro-sociological issues, and enable us to learn more about historical power and domination relations within the Amazonian dwellers in this region.

Keywords: enchanted people, Cobra Honorato, Brazil, Amazon, twins, narratives about extraordinary people, ethnology 
50 Des vies extraordinaires : les territoires du récit $-\mathrm{n}^{\circ} 79$

\section{A produção de entidades: Narrativas sobre o encantamento de uma pessoa extraordinária na Amazônia brasileira}

Resumo: O mito de Cobra Honorato e suas múltiplas variações são largamente conhecidos na Amazônia brasileira. Se trata das peripécias de uma Cobra Grande encantada e da sua irmã gêmea, casal nascido da união entre uma mulher e uma entidade subaquática. Na área rural de Santarém, no baixo Amazonas, essa trama narrativa informa de maneira recorrente os relatos produzidos sobre as trajetórias de vida de pessoas notáveis (como famosos curadores já falecidos). Ao falar sobre essas histórias, as populações trazem informações e dão vida à uma ampla rede de interconhecimento baseada sobre o parentesco, insistindo sobre dimensões espacial, histórica e sociológica. Mostrarei também como essas atualizações do mito se encaixam em questôes micro sociológicas, epermitem entender melhor as condiçôes históricas do estabelecimento de relaçôes de poder e de dominação existentes entre os moradores da região.

Palavras-chave : encantados, Cobra Honorato, Brasil, Amazônia, gêmeos, relato de vida extraordinária, etnologia

\section{Note sur l'auteur}

Émilie Stoll est anthropologue, docteure de l'École Pratique des Hautes Études et de l'Université Fédérale du Pará (Brésil). Elle réalise des recherches en Amazonie brésilienne auprès des populations indigènes et riveraines de la rivière Arapiuns depuis 2010. Elle est actuellement post-doctorante à l'Institut de Recherche pour le Développement, au sein de l'UMR 208 Paloc « Patrimoines locaux et gouvernance »IRD/MNHN. 